\title{
Virucidal efficacy of chlorhexidine: a systematic review
}

\author{
Matheus dos Santos Fernandez ${ }^{1}$ Maria Izabel Florindo Guedes ${ }^{2}$. Gerson Pedro José Langa ${ }^{3}$. \\ Cassiano Kuchenbecker Rösing ${ }^{3} \cdot$ Juliano Cavagni $^{3} \cdot$ Francisco Wilker Mustafa Gomes Muniz $^{4}$ (i)
}

Received: 10 May 2021 / Accepted: 26 September 2021 / Published online: 12 October 2021

(c) The Society of The Nippon Dental University 2021

\begin{abstract}
This study aimed to systematically review the literature about the virucidal efficacy of CHX in comparison to other substances used in the oral cavity. Electronic searches were performed in four databases (PubMed, Scopus, Embase, and Web of Science). Only studies that presented the following characteristics were included: (1) verified virucidal efficacy of CHX against Herpes Simplex Type-1 (HSV-1), any Influenza, or any human coronavirus (HcoV); and (2) compared the virucidal efficacy of CHX with essential oils (Listerine ${ }^{\circledR}$ ), quaternary ammonium compounds, povidone-iodine, hydrogen peroxide, negative control substance, and absence of therapy. Two researchers independently selected the studies, extracted data and evaluated the risk of bias. A narrative data synthesis was used. Twenty-five studies were included, of which 21 were in vitro and four were randomized clinical trials (RCT). Studies assessed the virucidal efficacy of CHX against Herpes Simplex Type-1 (HSV-1) (10 studies), Influenza A (InfluA) (4 studies), human coronavirus (HCoV) (4 studies) and Severe Acute Respiratory Syndrome-Related Coronavirus (SARS-CoV-2) (11 studies). Most studies demonstrated that CHX has a positive virucidal efficacy against HSV-1 and InfluA strains. However, lower efficacy was shown to InfluA strain in comparison to povidone-iodine. Lower to none virucidal efficacy of CHX is expected for $\mathrm{HCoV}$ and SARS-CoV-2 strains for in vitro studies. Three RCT demonstrated that CHX was able to significantly reduce the viral load of SARS-CoV-2 for a short period. CHX may present an interesting virucidal efficacy against HSV-1 and InfluA viruses. CHX also presents transient efficacy against SARS-CoV-2 when used as a mouthwash.
\end{abstract}

Keywords Antiseptics $\cdot$ Chlorhexidine $\cdot$ Mouthrinses $\cdot$ Mouthwashes $\cdot$ Virus

\section{Introduction}

Chlorhexidine (CHX) is widely used as an antiseptic formulation in dental practice [1]. CHX is a dicationic biguanide, and its use in children and adults has provided fast-acting and excellent safety $[2,3]$. This product is commercially

Francisco Wilker Mustafa Gomes Muniz wilkermustafa@gmail.com

1 School of Dentistry, Federal University Pelotas (UFPel), Rua Gonçalves Chaves, 457, Pelotas, RS 96015-560, Brazil

2 Biotechnology and Molecular Biology Laboratory, State University of Ceará (UECE), Av. Dr. Silas Munguba, 1700, Fortaleza, CE 60714-903, Brazil

3 Department of Periodontology, Federal University Rio Grande do Sul (UFRGS), Rua Ramiro Barcelos, 2492, Porto Alegre, RS 90035-003, Brazil

4 Department of Periodontology, Federal University Pelotas (UFPel), Rua Gonçalves Chaves, 457, Pelotas, RS 96015-560, Brazil available in various concentrations and presentations. In contrast to other antiseptic agents, the residual antimicrobial activity of $\mathrm{CHX}$ is unaffected by the presence of body fluids and blood $[4,5]$.

Many studies have established a clinically relevant antiplaque and antigingivitis efficacy of $\mathrm{CHX}$ in a dental clinical setting [6, 7]. For these reasons, $\mathrm{CHX}$ is recommended as the gold standard mouthrinse for chemical control of supragingival biofilm. Other studies have also reported positive results of $\mathrm{CHX}$ in reducing the proliferation of bacterial species associated with periodontal disease $[6,8]$. This product also reduces the levels of halitosis-related bacteria colonizing the tongue's dorsal surface $[9,10]$. However, the adverse events of CHX limit the long-term use of this mouthwash, which includes taste alteration, formation of supragingival calculus, soft tissue lesions in young patients, allergic responses, and staining of teeth and soft tissues [11, 12].

$\mathrm{CHX}$ is also suggested as a preprocedural mouthrinse to control the infection and reduce the number of bacteria in 
aerosol $[13,14]$ since important effects in a broad spectrum of Gram-positive and Gram-negative bacteria were demonstrated $[2,3,15]$. Therefore, considering that CHX may also be effective against lipid-enveloped microorganisms, different authors have also investigated the effectiveness of CHX against viral strains. Therefore, CHX may be a viable candidate to prevent or treat virus infection in the oral cavity, but no synthesized information is available about the virucidal efficacy of CHX. Therefore, this study aimed to systematically review the literature about the virucidal efficacy of CHX in viruses that affects the oral cavity.

\section{Materials and methods}

The report of this systematic review is based on the Preferred Reporting Items for Systematic Reviews and Metaanalyses (PRISMA) 2020 statement [16].

\section{Focused question}

The present study is based on the following focused question: "Does chlorhexidine have significant virucidal effect, as compared to other solutions or a placebo solution, in viruses affecting the oral cavity?". Therefore, the PICO question for this systematic review was defined as follows:

P: Any population and in vitro assays involving viruses that affect the oral cavity.

I: Use of chlorhexidine in any concentration and formulation.

C: Absence of therapy, placebo solution, hydrogen peroxide, povidone-iodine, any quaternary ammonium compounds or essential oils (Listerine ${ }^{\circledR}$ ).

$\mathrm{O}$ : Any assessment of virucidal efficacy in the following virus: Herpes Simplex Type-1 (HSV-1), Influenza A, Human coronavirus $(\mathrm{HCoV})$ and Severe Acute Respiratory Syndrome-Related Coronavirus (SARS-CoV-2) strains.

\section{Search strategy and selection of studies}

All articles were selected from the following electronic databases: PubMed, Web of Science, Embase and Scopus. Sensitivity analysis strategies were developed for each database using a combination of free terms and, whenever applicable, indexed specifically to each database. The search strategy was performed on July 9th, 2021. Hand searching of the reference lists of all studies included in the search strategy and in the reference list of previously published reviews was performed [14, 17-19]. The full search strategy for all databases can be found in Appendix 1. A search for grey literature was also performed on Google Scholar database using an adapted search strategy. Only the first 100 studies were screened for eligibility on this database.

Studies that performed any in vitro microbiological analysis that used cells or surfaces contaminated by these viral agents were also screened for eligibility, as well as clinical trials that assessed the virucidal efficacy of CHX. The exclusion criteria were review articles, case reports, letters to the editor and observational studies. Studies that associated CHX with another therapy in the same group, those who evaluated other viruses or those studies without the abovementioned control groups were also excluded. No restriction of language or date of publication were applied.

Results of literature searches were uploaded in Endnote ${ }^{\odot}$ X9 software (Thomson Reuters, New York, NY, USA), and duplicate records were removed. Two researchers (FWMGM and GPJL) independently screened all titles and abstracts considering the abovementioned eligibility criteria. The same two researchers independently assessed the full text of the included studies, and discrepancies were solved by a third researcher (CKR). Regarding study selection, kappa coefficients between the two researchers were 0.976 and 0.957 for title/abstract and full-text selection, respectively.

\section{Data extraction}

Data extraction was conducted using a standardized Excel spreadsheet $\left(\right.$ Microsoft ${ }^{\circledR}$ ) specifically developed for this study. The following data were extracted: author, year, country, study design, CHX and control solution concentrations, the form of administration, contact time of all tested solutions, virus assessed, and origin of the virus. In addition, the test used to determine the virucidal efficacy, results of virus inactivation in the CHX group, results of virus inactivation in the control groups, main results, and other important observations were also evaluated. Two researchers extracted all data independently (FWMGM and MSF), and a third reviewer was involved only in case of discrepancy (MIFG).

\section{Risk of bias and synthesis of evidence}

The risk of bias of all included studies was assessed independently by two researchers (FWMGM and MSF), following the criteria proposed by the Joanne Briggs Institute [20]. When a consensus was not possible, a third researcher was involved in this process (GPJL). The checklist was adapted according to the statements proposed by CRIS Guidelines (Checklist for Reporting In-Vitro Studies) [21], which suggests evaluating factors such as the randomization process, blinding and statistical analysis. The tool has ten questions, two of which were not considered for the present study because they do not agree with the risk of bias analysis for 
in vitro studies. Therefore, the following questions were evaluated:

(1) Was the assignment to treatment groups truly random?

(2) Was allocation to treatment groups concealed from the allocator?

(3) Were those assessing the outcomes blind to the treatment allocation?

(4) Were control and treatment groups comparable at entry?

(5) Were groups treated identically other than for the named interventions?

(6) Were outcomes measured in the same way for all groups?

(7) Were outcomes measured in a reliable way?

(8) Was appropriate statistical analysis used?

Each question was answered and when enough information was available, a "Yes" answer was given, which is equivalent to a low risk of bias. In case of non-existent information, the "No" answer was given for this criterion, the equivalent of a high risk of bias. The "not clear" response was attributed when a high or low risk of bias could not be classified. For each "Yes" attributed to each criterion, the study received one point.

For randomized clinical trials (RCT), the Cochrane risk of bias tool for randomized trials (RoB 2) was used [22]. The tool evaluates the risk of bias considering six different domains: random sequence generation, deviations from the intended interventions, missing outcomes, measurement of the outcome and selective outcome reporting.

Due to the high heterogeneity among the included studies, no meta-analysis could be performed. Therefore, data synthesis is presented in a qualitative way.

\section{Results}

The searches performed in the electronic databases presented 2,662 potentially relevant studies [PubMed $(n=1,225)$; Scopus $(n=1741)$; EMBASE $(n=1562)$; Web of Science $(n=351)]$. From these, 196 full-texts were read, of which 170 were excluded. Therefore, 26 studies were included in this systematic review. Seven evaluated the virucidal effect of CHX only against HSV-1 [23-29] and three studies verified the effect on HSV-1 and Influenza A [30-32]. In addition, another four studies investigated the virucidal effect from $\mathrm{CHX}$ in $\mathrm{HCoV}$ strains [33-36]. Ten studies assessed the virucidal efficacy of CHX against SARS-CoV-2 [37-46]. One study assessed the virucidal efficacy of CHX against SARSCoV-2 and Influenza A [47]. Figure 1 shows the flowchart of study inclusion. In general, the included studies were published between 1972 and 2021.

\section{Risk of bias}

All in vitro studies presented an unclear risk of bias for randomization, allocation concealment, and blinding of the evaluators (Fig. 2) [23-38, 40, 44-47]. Based on RoB 2 assessment, overall low risk of bias was detected in two studies [41, 42]. The other RCTs presented some concerns [43] and high [39] risk of bias. Figure 3 shows the risk of bias assessment for these studies.

\section{Efficacy of CHX against HSV-1}

Table 1 summarizes the main findings of all studies that evaluated the virucidal effect of CHX against HSV-1. In these assays, the concentration of $\mathrm{CHX}$ varied from $0.001 \%$ [26, 27] to $2.5 \%$ [25]. The main method of administration of CHX was direct contact with cells contaminated by HSV-1, and the time of exposure to the virus varied significantly among the included studies.

All studies presented a control group that could be composed of contaminated cells that were exposed to antiseptic solutions [26-28, 30], samples exposed to a placebo solution, without an active agent [31], or to sterile phosphatebuffered saline [23]. Other substances were also used, such as essentials oils [24], povidone-iodine [25, 29, 32], hydrogen peroxide [25], and quaternary ammonium compounds, Ethylenediaminetetraacetic acid (EDTA) [29]. Most of the viral samples used in the studies were obtained from culture collection organizations, cultivation from other laboratories and distributed standard reference microorganisms [23-28, $31,32]$. Two studies did not report the origin of the viral samples used in their experiments [29, 30].

All studies were in vitro, and the most used test to verify the virucidal efficacy of CHX against viral agents was minimum inhibitory concentration by viral titration [25, 26, 28-32] and colony-forming units [24, 27], followed by the sensitivity of tissue culture cells [23]. Regardless of the CHX's concentration, significant virucidal efficacy was demonstrated in studies that used viral titration reduction tests when compared to a control group of contaminated cells that did not receive any antiseptic solution $[28,30]$ and to those exposed to a placebo solution [31]. Other studies that used the same methodology demonstrated that CHX showed low [26] or uncertain [25, 29, 32] efficacy to inhibit HSV-1 viral replication when compared to cells that had no contact with disinfectants [26] or exposed to povidone-iodine [25, 
Fig. 1 Flow chart of studies selection according to PRISMA statement

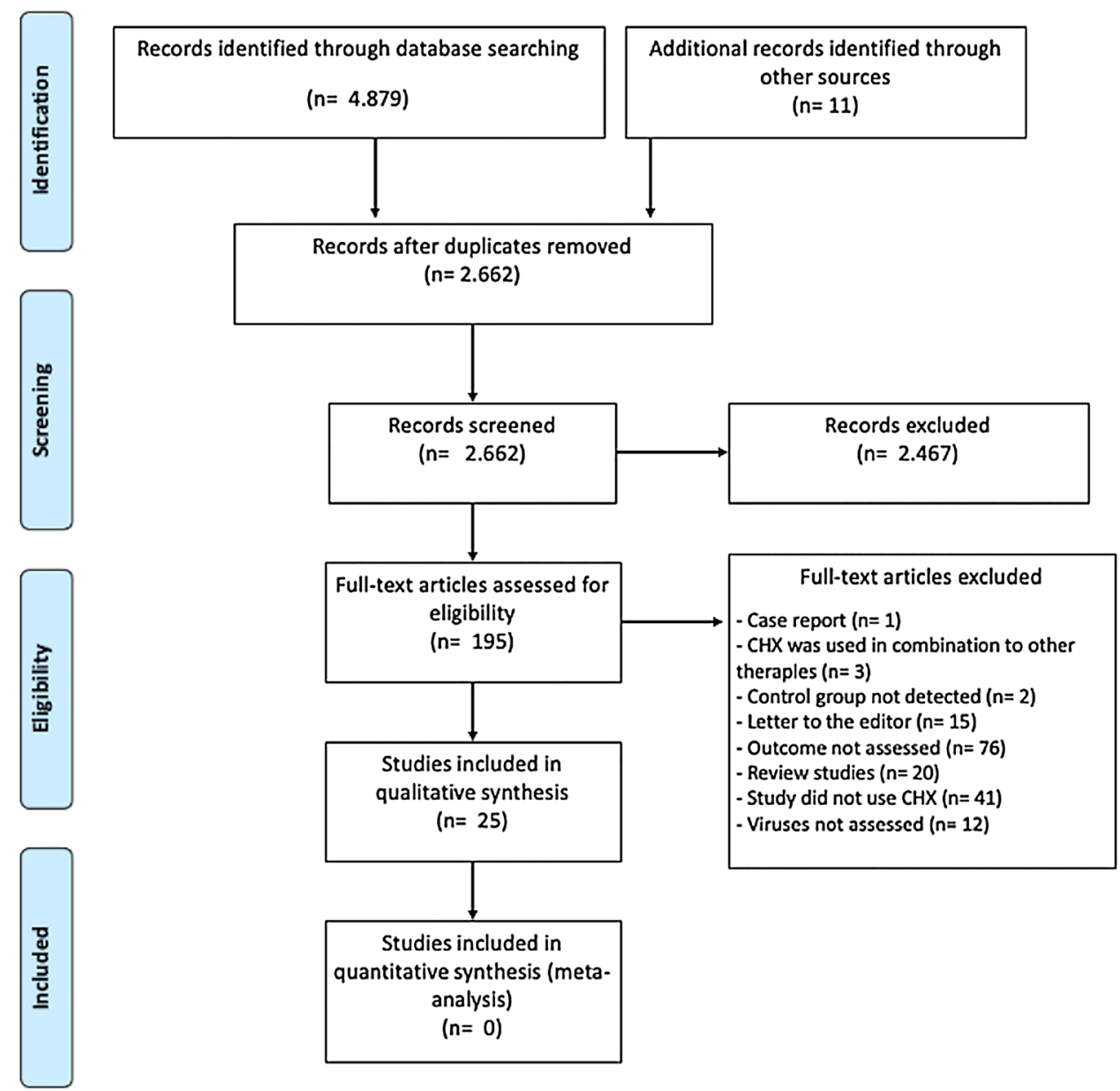

29, 32], respectively. The study that assessed the sensitivity of tissue culture cells demonstrated that $\mathrm{CHX}$ has superior virucidal efficacy compared to a sterile phosphate-buffered saline solution [23].

Moreover, other studies that evaluated the effect of CHX compared to uncontaminated cells and exposed to sterile phosphate-buffered saline by means of colony-forming units and sensitivity of tissue culture cells found that CHX is a viable alternative for the reduction of HSV-1 viral load [24, 27]. Regarding the virucidal effect of $\mathrm{CHX}$ compared to essential oils, both solutions showed similar and effective anti-HSV-1 properties [24].

\section{Efficacy of CHX against Influenza $A$ and coronavirus (HCoV and SARS-CoV-2)}

Five studies evaluated the virucidal effect of CHX against Influenza A strains [30-33, 47] (Table 2). Of these, three studies also verified the virucidal efficacy of the antiseptic against HSV-1. These studies were previously characterized
[30-32]. One study [33] verified the viral sensitivity by analyzing the detection inoculation of samples in cell culture and nested multiplex RT-PCR. For this, cells infected by the viruses were exposed to $\mathrm{CHX}$, while another group of infected cells did not receive solutions with disinfectant agents [33]. Disinfectant effectiveness of CHX was assessed by titrating Influenza A on a model using skin tissues [47]. In vitro inactivation of Influenza A was also tested in this study [47].

In general, studies demonstrated the effectiveness of CHX in reducing the viral load of Influenza A after $30 \mathrm{~s}$ [31,33] and after 10 min of contact [30], when compared to groups of contaminated cells that had no contact with disinfectants $[30,33]$ or exposed to CHX without the active agent [31]. Notwithstanding, one study [32] demonstrated that, compared to povidone-iodine solution and gargle, $\mathrm{CHX}$ might also be a viable alternative against the Influenza A virus [32]. Another study demonstrated a low virucidal efficacy of CHX against Influenza A viruses on both skin and in vitro models [47]. 


\begin{tabular}{|c|c|c|c|c|c|c|c|c|}
\hline \multirow{2}{*}{ Author (Year) } & \multicolumn{8}{|c|}{ Joanne Briggs Institute (JBI) } \\
\hline & (1) & (2) & (3) & (4) & (5) & (6) & (7) & (8) \\
\hline Ansaldi et al., 2004 & $?$ & $?$ & $?$ & + & + & + & + & - \\
\hline Bailey \& Longson, 1972 & $?$ & $?$ & $?$ & + & + & + & + & - \\
\hline Baqui et al., 2001 & $?$ & $?$ & $?$ & + & + & + & + & - \\
\hline Bernstein et al., 1990 & $?$ & $?$ & $?$ & + & + & + & + & - \\
\hline Davies et al., 2021 & ? & $?$ & $?$ & + & + & + & + & - \\
\hline Damery \& Cremieux, 1989 & $?$ & $?$ & $?$ & + & + & + & + & - \\
\hline Geller et al., 2009 & $?$ & $?$ & $?$ & + & + & + & + & + \\
\hline Hirose et al., 2021 & $?$ & $?$ & $?$ & + & + & + & + & - \\
\hline Imai et al., 2021 & $?$ & $?$ & $?$ & + & + & + & + & - \\
\hline \begin{tabular}{|l} 
Jain et al., 2021 \\
\end{tabular} & $?$ & $?$ & $?$ & + & + & + & + & - \\
\hline Kawana et al., 1997 & $?$ & $?$ & $?$ & + & + & - & $?$ & + \\
\hline Komine et al., 2021 & $?$ & $?$ & $?$ & + & - & + & + & - \\
\hline Meister et al., 2020 & $?$ & $?$ & $?$ & + & + & + & + & - \\
\hline Okunishi et al., 2009 & $?$ & $?$ & $?$ & + & + & + & $?$ & - \\
\hline Park \& Park, 1989 & $?$ & $?$ & $?$ & + & + & + & + & - \\
\hline Park et al., 1991 & $?$ & $?$ & $?$ & + & + & + & + & - \\
\hline Sattar et al.,1989 & $?$ & $?$ & $?$ & + & + & + & + & + \\
\hline Steinhauer et al., 2021 & $?$ & $?$ & $?$ & + & - & + & + & - \\
\hline Shinkai \& Yoshino, 1974 & $?$ & $?$ & $?$ & + & + & + & + & - \\
\hline Tyler \& Ayliffe, 1987 & $?$ & $?$ & $?$ & + & + & + & + & - \\
\hline Xu et al., 2020 & $?$ & $?$ & $?$ & + & + & + & + & + \\
\hline \multicolumn{8}{|c|}{ JBI - Critical appraisal checklist for In-Vitro Studies } & \\
\hline \multirow{4}{*}{\multicolumn{5}{|c|}{$\begin{array}{l}\text { (1) Was the assignment to treatment groups truly random? } \\
\text { (2) Was allocation to treatment groups concealed from the allocator? } \\
\text { (3) Were those assessing the outcomes blind to the treatment allocation? } \\
\text { (4) Were control and treatment groups comparable at entry? } \\
\text { (5) Were groups treated identically other than for the named interventions? } \\
\text { (6) Were outcomes measured in the same way for all groups? } \\
\text { (7) Were outcomes measured in a reliable way? } \\
\text { (8) Was appropriate statistical analysis used? }\end{array}$}} & & \multicolumn{3}{|c|}{ Legend } \\
\hline & & & & & & + & Yes & \\
\hline & & & & & & - & No & \\
\hline & & & & & & & Unclear & \\
\hline
\end{tabular}

Fig. 2 Risk of bias of the in vitro included studies
The resistance of $\mathrm{HCoV}$ against the virucidal action of CHX was evaluated in four studies [33-36]. Minimum inhibitory concentration by viral titration was the main test to verify the virucidal effect of the antiseptic on cells [34] and stainless steel disc surfaces [35] contaminated with the virus, except for one study [33]. One study assessed the viral titers reduction after exposure to $\mathrm{CHX}$ [36].

Detection analyses by inoculation of samples in cell culture demonstrated no virucidal efficacy after $30 \mathrm{~s}$ of contact with $\mathrm{CHX}$ when a culture of $\mathrm{HCoV}$ was used. Similar results were detected, in another study, after $15 \mathrm{~s}, 30 \mathrm{~s}$, and $60 \mathrm{~s}$ [36]. However, a different result was obtained when RT-PCR was applied, as CHX inactivated the viruses after $30 \mathrm{~s}$ [33]. Nevertheless, the results of viral titration tests in plaque-forming units reflect that $\mathrm{CHX}$ has moderate antiHCoV activity [34] or is ineffective [35] when compared to the results of contaminated samples not exposed to disinfectants (Table 2).

Eleven included studies verified the antiviral efficacy of CHX on SARS-CoV-2 strains, of which seven were in vitro studies [37, 38, 40, 44-47], and four were RCT [39-42]. One study [37] verified the viral infectivity of SARS-CoV-2 after contact with two different products based on $0.02 \% \mathrm{CHX}$ (Chlorhexamed Forte ${ }^{\circledR}$ and Dynexidine Forte ${ }^{\circledR}$ ). Through viral titers determined upon titration on Vero cells, the study demonstrated that CHX (regardless of the tested product) has not been able to significantly reduce the viral infectivity of the three strains of SARS-CoV-2 in comparison to other evaluated solutions (hydrogen peroxide, povidone-iodine and essential oils) [37]. Moreover, CHX was not able to significantly reduce the viral titers in two other studies, using $0.12 \%$ [45] or $0.2 \%$ diluted or not in alcohol [40]. Conversely, these studies showed that essential oils (Listerine)
Fig. 3 Risk of bias assessment of included the randomized controlled trials
Eduardo et al., 2021

Elzien et al., 2021

Huang et al., 2016

Seneviratne et al., 2020

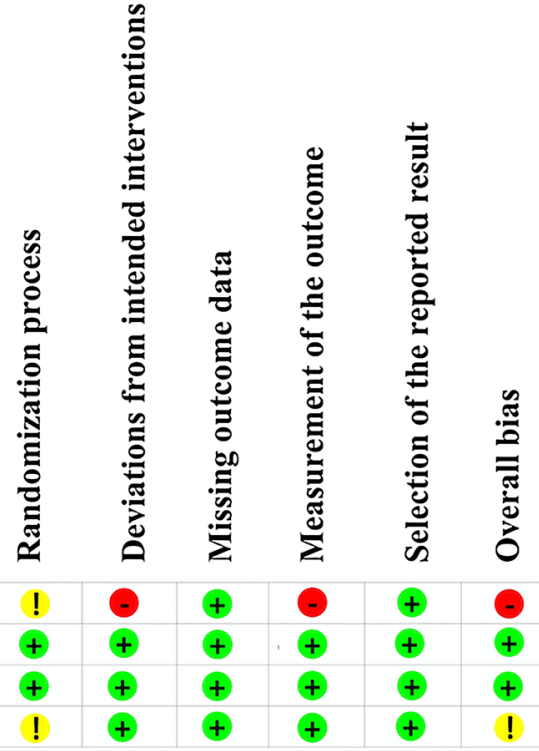




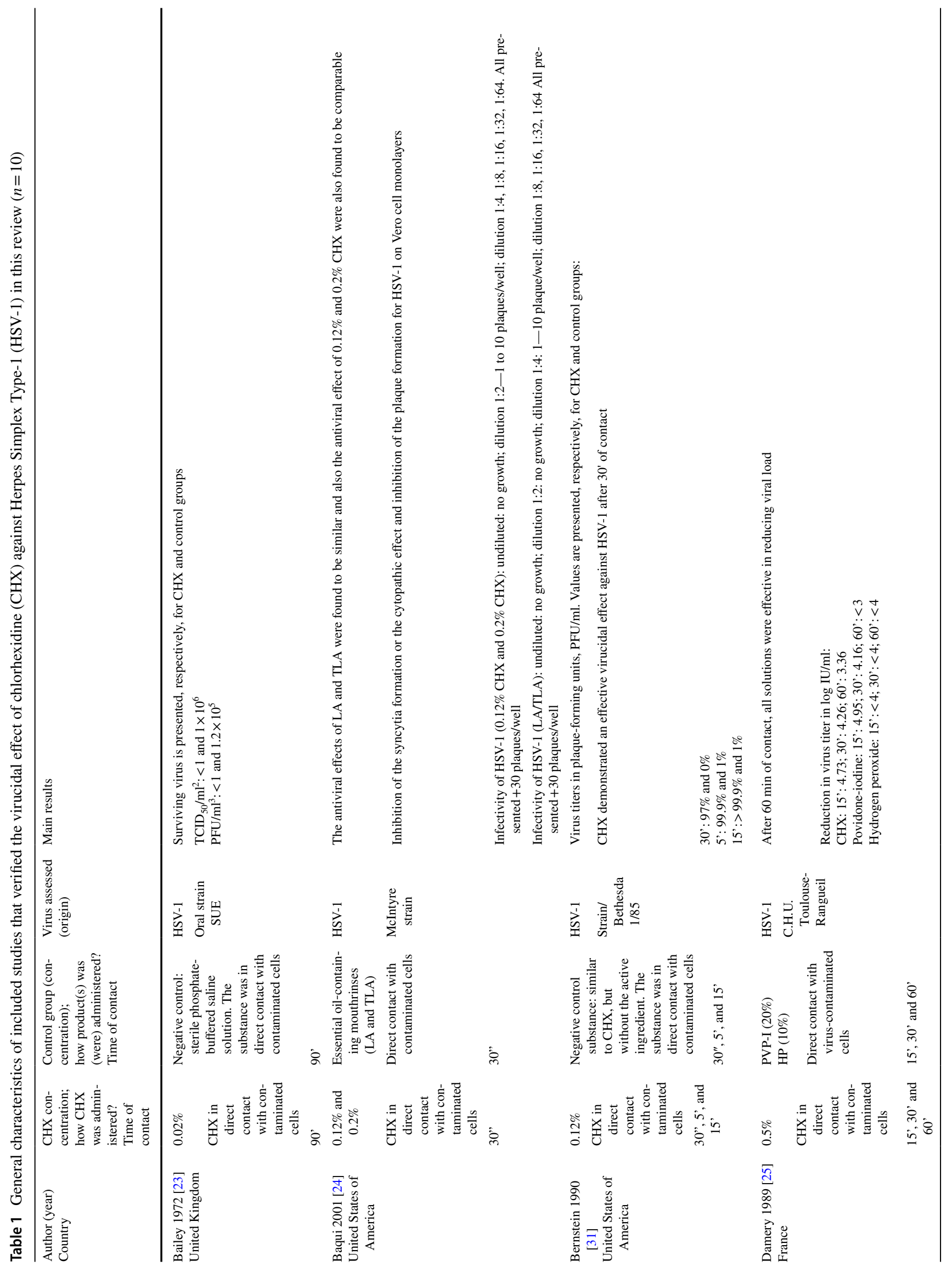




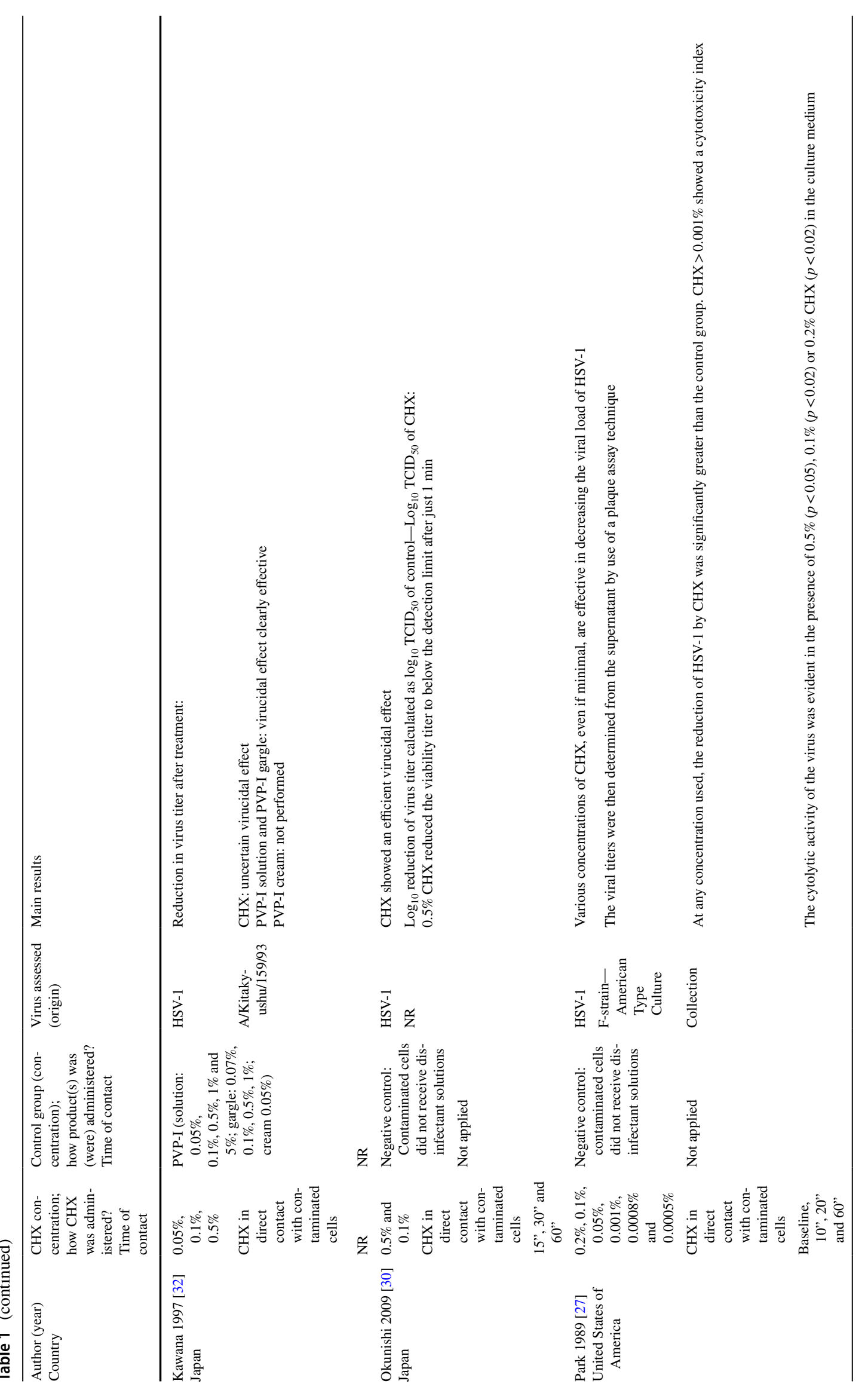




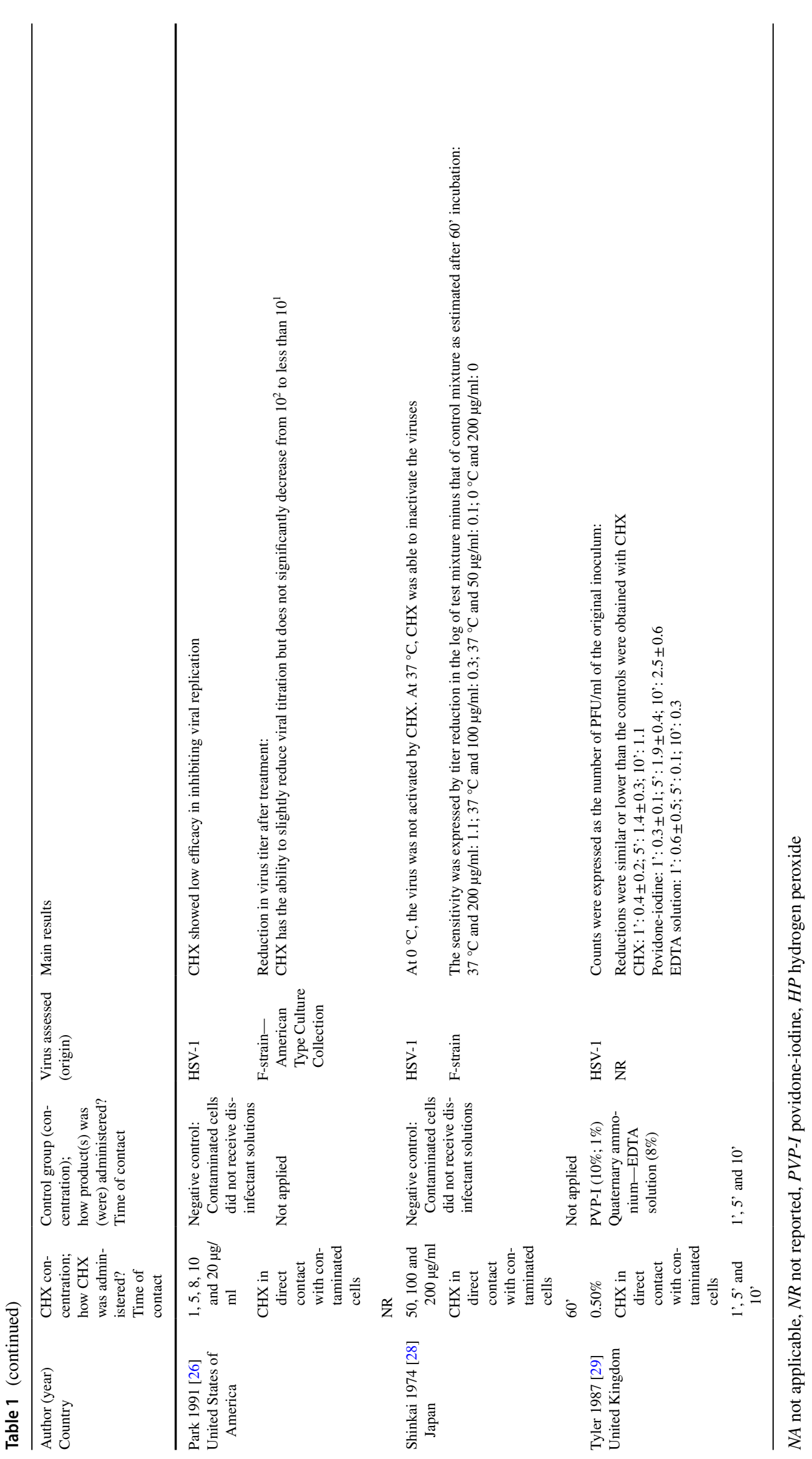



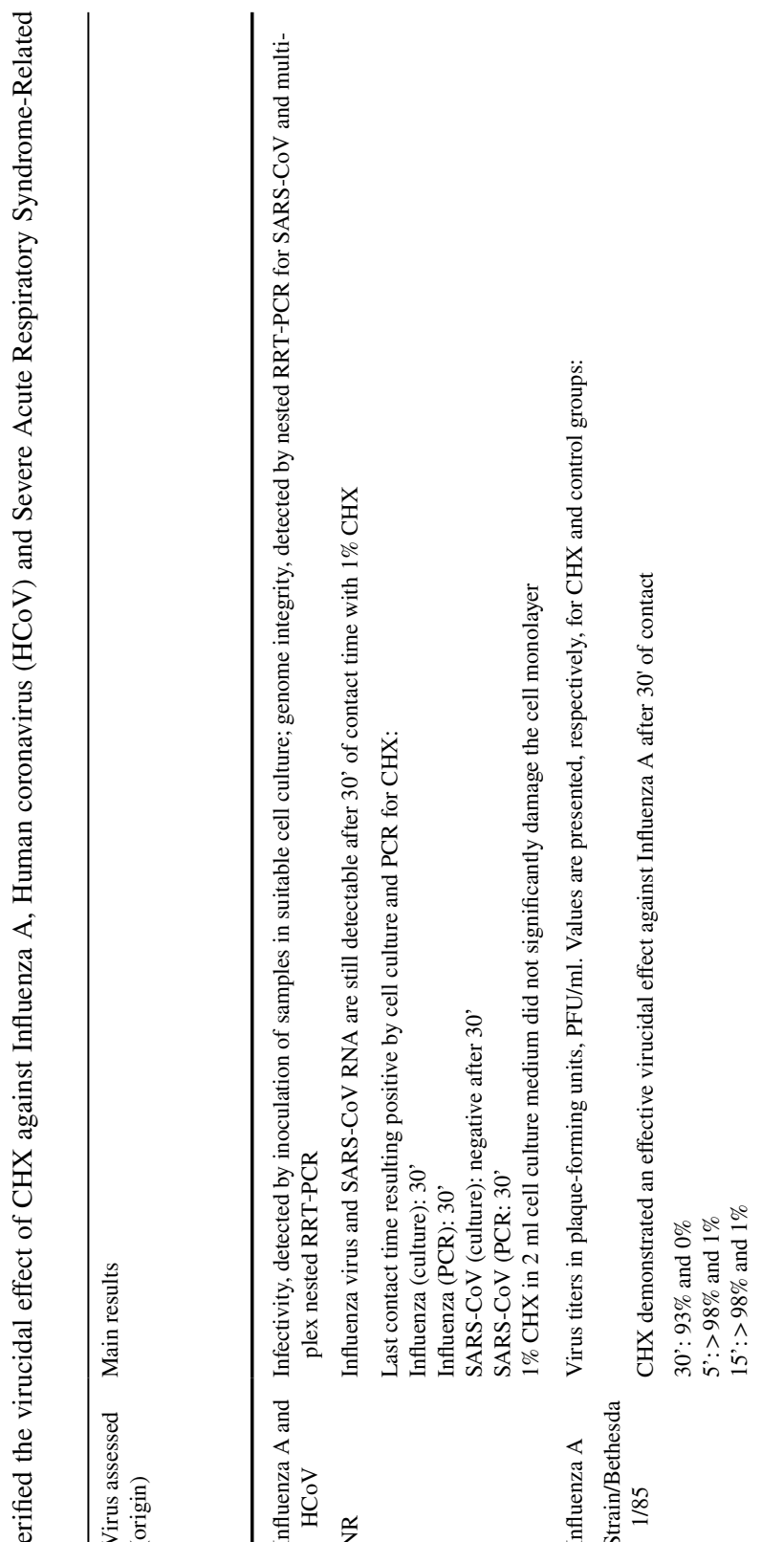

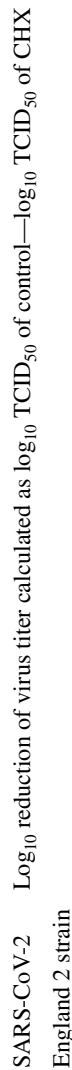
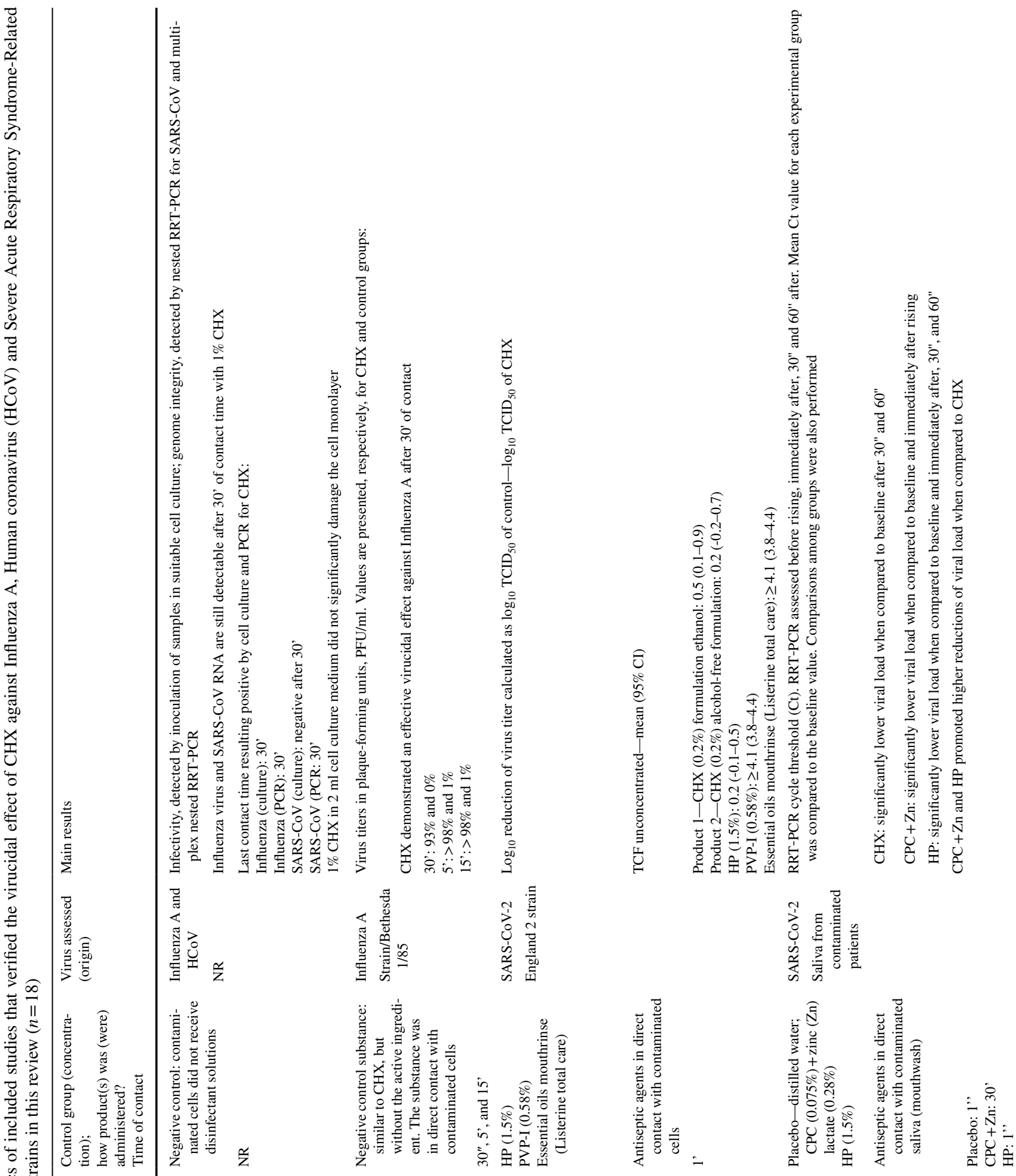

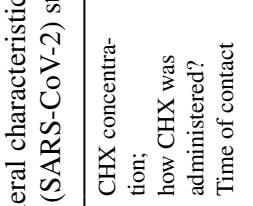

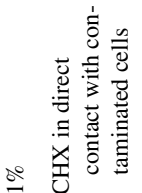

in
in
i.
$\vdots-0$
$\vdots=$

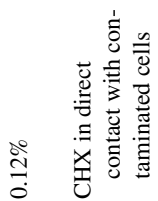

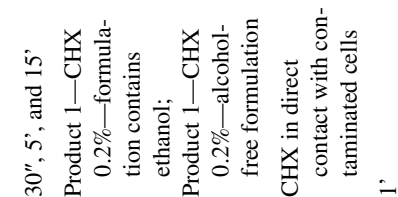

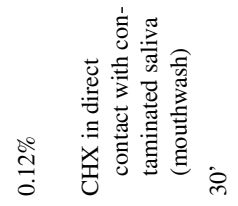

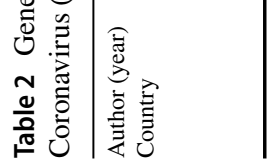

高

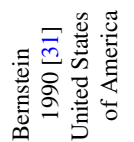

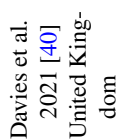

焉王 


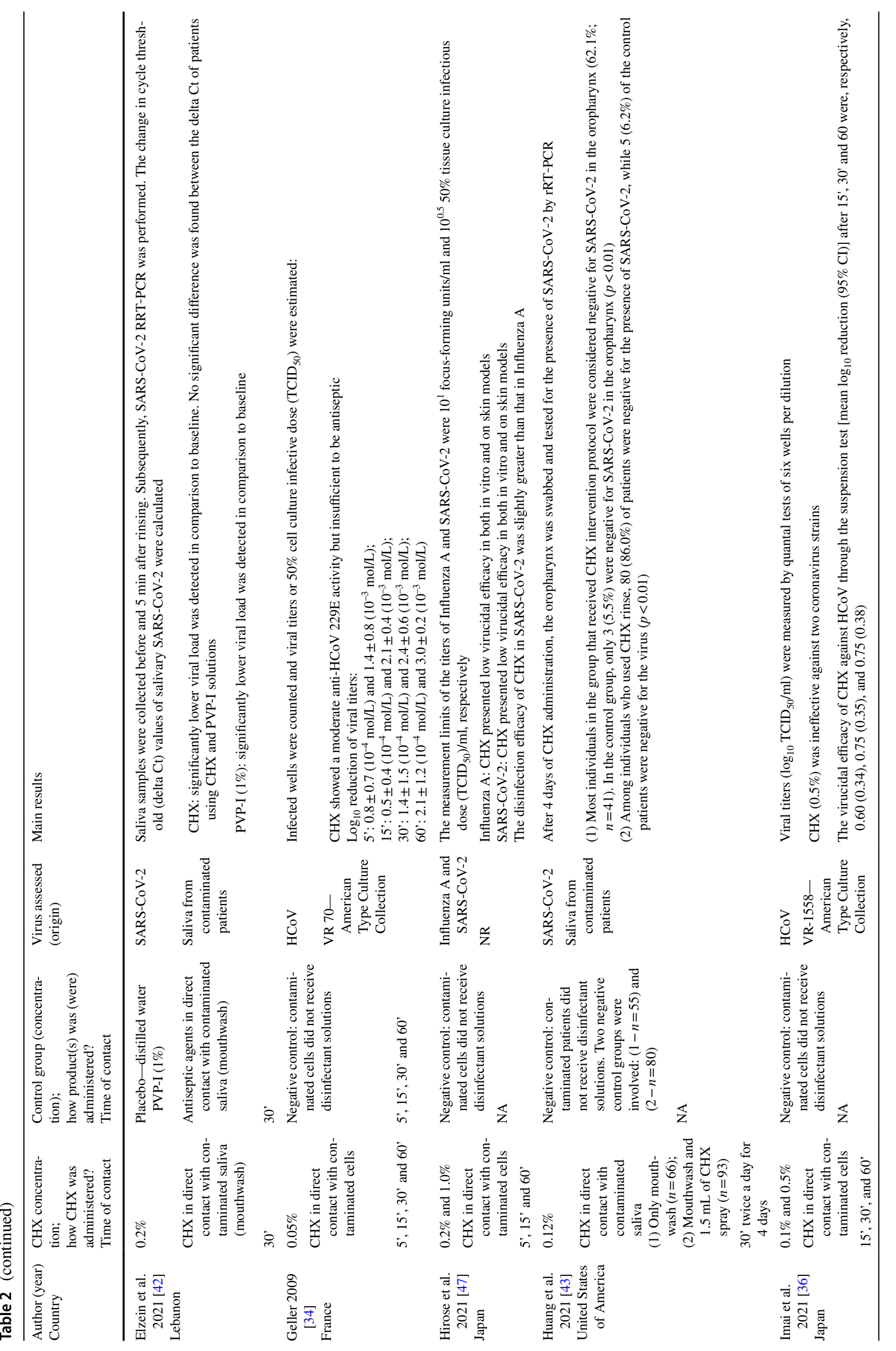




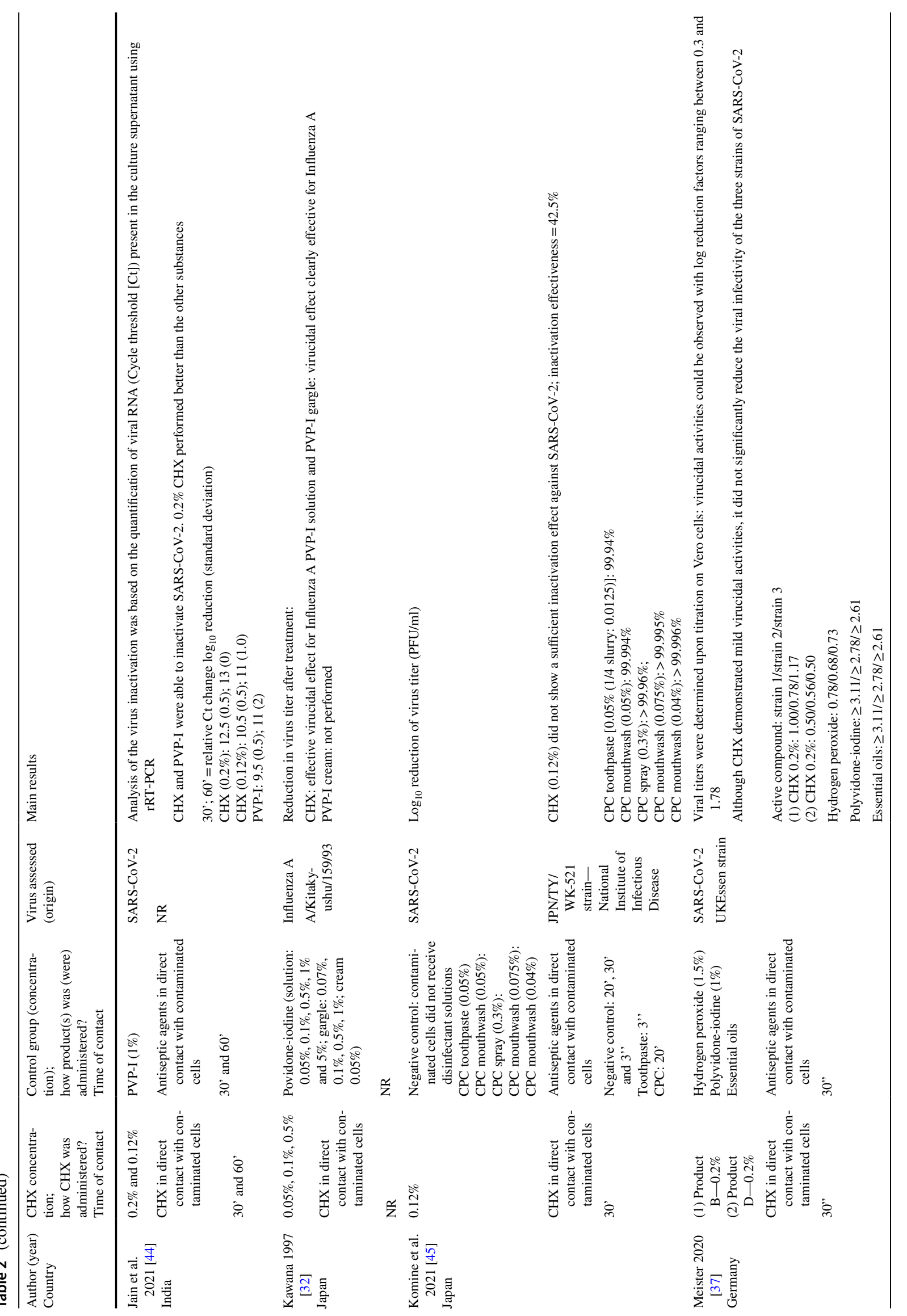




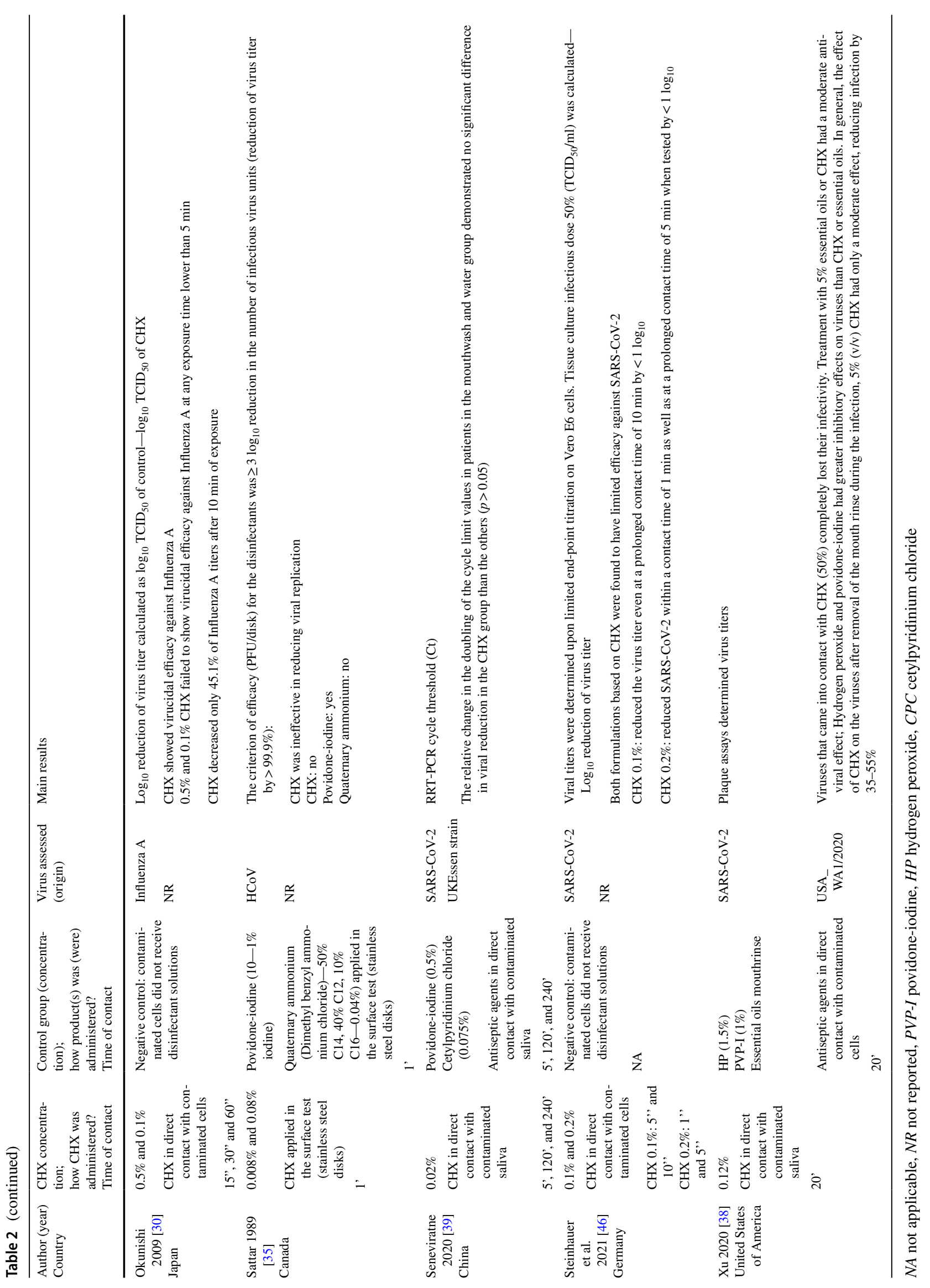


[40], povidone-iodine [40], and cetylpyridinium chloride were able to significantly SARS-CoV-2 strains [45].

Another study [38] investigated the infectivity of viral strains present in saliva after exposure to $\mathrm{CHX}$ solution. It was demonstrated that those viruses that came into contact with CHX (1.5\%) completely lost their infectivity. In addition, treatment with 5\% CHX had a moderate antiviral effect. Hydrogen peroxide and povidone-iodine had greater inhibitory effects on viruses than CHX. In general, CHX significantly blocked viral infectivity.

The efficacy of CHX against SARS-CoV-2 was also demonstrated in lower concentrations, such as $0.2 \%$, inactivating $>99.9 \%$ of the viruses after $30 \mathrm{~s}$ and $60 \mathrm{~s}$ [44]. However, different results were also detected in the literature, as low $[46,47]$ virucidal efficacy was also seen in three other studies, using $0.1 \%$ to $1.0 \%$ CHX.

Still, in this context, three recent RCTs evaluated the efficacy of CHX in reducing the salivary SARS-CoV-2 viral load in patients diagnosed with coronavirus disease 2019 (COVID-19) [39, 41, 42]. One study assessed the reduction of the viral load of SARS-CoV-2 in the oropharynx [43]. It is important to highlight that these studies included patients with no need for nasogastric or endotracheal intubation. The time-lapse between COVID-19 diagnosis and inclusion in the trial was short. The reduction in viral load was measured using the rRT-PCR Cycle threshold (Ct) technique. Ct values are proportional inversely to viral load in this technique and can provide an indirect method of quantifying the copy number of viral RNA in the sample. It was observed that CHX demonstrated heterogeneous virucidal efficacy against SARS-CoV-2 present in saliva in one study [39]. After a single-use, the antiseptic failed to significantly reduce viral load when compared to the viral reduction observed in groups exposed to povidone-iodine, cetylpyridinium chloride and water [39].

Conversely, another study demonstrated a significantly lower viral load in the CHX group when compared to a control group (distilled water) [42]. This study also showed no significant difference when $\mathrm{CHX}$ and povidone-iodine were compared [42]. Another study also showed that a single rinse with CHX significantly reduced the viral load of SARSCoV-2 after $30 \mathrm{~min}$ and $60 \mathrm{~min}$ [41]. However, this study showed that higher reductions in viral load were detected in individuals that rinsed with hydrogen peroxide or with cetylpyridinium chloride + zinc mouthwashes [41].

The study that assessed the reduction in viral load of SARS-CoV-2 in the oropharynx compared rinsing with CHX to standard care only [43]. A combination of spray and mouthwash with CHX was also compared to a standard care. In both test groups, rinse with CHX was performed for 4 days, and, in comparison to the control group, a number significantly higher of patients with negative detection of SARS-CoV-2 in the oropharynx was detected [43]. It is important to highlight that all RCT reported no adverse events after a single use or after 4 days use of CHX.

\section{Discussion}

The present study aimed to systematically review the literature about the virucidal efficacy of $\mathrm{CHX}$ for some strains of viruses. Based on in vitro studies, it was demonstrated that CHX might reduce the levels of HSV-1 and Influenza A viruses, but lower to none in vitro effect may be expected to HCoV and SARS-CoV-2. In addition, a transient efficacy of CHX may be expected in patients diagnosed with COVID19. It must be acknowledged that, among the included studies, the standards of testing such products were considerably heterogeneous, and the combination of data from different studies with the aforementioned draws peril for veritable comparisons. It may be hypothesized that the biophysiological mechanisms for the virucidal effect of CHX are the lysis of viral envelope, deterioration of nucleotide carbon chains, and impact on the inactivation and/or blocking of viral proteins $[17,24,38]$, which may explain the efficacy against all the viruses tested in the present study.

The antiplaque and antigingivitis efficacy of CHX has been widely proven in the literature $[6,7]$. In addition to these important effects, CHX can also reduce bacteria levels in aerosol [14]. The use of CHX is not restricted to Dentistry, as the literature demonstrates a reduction in the incidence of ventilator-associated pneumonia in adults [48] and prevention of infection in clean surgeries in adults [49]. In addition, vaginal cleansing with CHX demonstrated lower morbidity rates in post-cesarean [50]. Despite this knowledge, the present study is the first systematic review to assess the virucidal efficacy of $\mathrm{CHX}$ on human viruses affecting the oral cavity.

Greater efficacy of CHX against HSV-1 viruses was demonstrated in the present study. The clinical feature of HSV-1 infection is characterized by the appearance of vesicles on the skin or mucous membranes of the mouth and lips. This virus is mainly transmitted by oral-to-oral contact, but the occurrence of these lesions in the genital area may also be detected. However, this is highly attributed to the infection of HSV-2 [51]. HSV-1 structure is relatively large, presenting a linear DNA genome wrapped in a lipid bilayer, the envelope. Therefore, it may be speculated that the antiviral efficacy of CHX on enveloped viruses may be similar to the one observed in the cytoplasmic membrane of bacteria [52].

It is estimated that approximately $66.6 \%$ in those aged 0-49 years are living with HSV-1 in the world [53]. The literature reports that topical antiviral agents showed no efficacy in preventing herpes simplex labialis in individuals of all ages [54]. This is of utmost importance as HSV-1 infections may be self-limited. However, the HSV-1 vesicles 
are very painful and may delay dental treatment when clinically detected. As an interesting effect of CHX was detected against this virus, further clinical trials are needed to establish these findings.

Another virus whose effect of CHX has been studied is Influenza A that is responsible for a disease transmitted through air, which causes fever, fatigue and sore throat. This virus is from the Orthomyxoviridae family and it has a negative sense RNA. Although infections with this virus are most common among birds [55], it also affects humans, which originated the 2009 pandemic of H1N1 [56]. A high hospitalization rate and hospitalization fatality risk are associated with these viruses, especially in developing countries [56].

The literature has demonstrated that saliva samples may be an excellent predictive tool for H1N1 [57], making mouthrinses very important to decrease contaminated aerosol with this virus. Only three included studies assessed the virucidal efficacy of CHX against Influenza A, and all of them demonstrated the CHX has excellent efficacy in inactivating this virus. The results were detected after $30 \mathrm{~s}$ to 10 min of contact with CHX. It is strongly recommended to perform clinical trials that may confirm these results using the appropriate time of rinsing with CHX.

Patients infected with SARS-CoV-2 may unknowingly spread the virus during the subclinical period by droplets. The literature shows a higher concentration of SARS-CoV-2 may be detected in saliva, salivary gland [58] and in the gingival crevicular fluid [59]. An agreement of $100 \%$ for the detection of SARS-CoV-2 nucleic acids using real-time reverse transcription PCR (RT-PCR) between samples of saliva and nasal swabs has also been reported [60]. In this sense, it has been proposed that saliva may be a possible tool for SARS-CoV-2 detection [61]. Therefore, a mouthrinse able to reduce the viral load in the mouth or, more specifically, in saliva may be necessary during dental procedures that produce aerosol.

Among the included studies, the in vitro virucidal efficacy of $\mathrm{CHX}$ against both $\mathrm{HCoV}$ and SARS-CoV-2 viruses was determined as lower to none. One RCT demonstrated that the reduction of viral load is similar to the one observed in water [39]. However, one prospective clinical trial, which did not use a control group, demonstrated that a high level of viruses is detected in the saliva, but CHX was able to significantly decrease the viral load for $2 \mathrm{~h}$ after a single-use [62]. Similar results were also detected in the other three RCT, of which one demonstrated a significantly higher number of patients with negative detection of SARS-CoV-2 [43].

In all clinical trials, a low number of participants were included, which decrease the clinical applicability of these findings. Other substances, such as povidone-iodine [63] and hydrogen peroxide [64], might be an additional benefit against SARS-CoV-2, but their clinical efficacy remains unproved $[65,66]$. It is noteworthy that the reduced timespan for the performance of large randomized clinical trials related to SARS-CoV-2, since it has been identified recently, could explain the scarcity of the literature. In addition, this might hinder possible effects to be determined in the future.

The present study looked at the effects of CHX on viruses. The interest in such effect stands beyond the control of COVID-19. The virucidal effect of an oral antiseptic is of interest in different biosafety procedures in the dental office and also in the disinfection of material used in oral prostheses. In addition, the concentrations of CHX varied between 0.001 [27] and $1.0 \%[33,47]$ among the included studies. The clinical efficacy of CHX has been proven with at least $0.12 \%$ [67], and these different concentrations may also explain the results detected. It is important to highlight that only a few viruses were assessed, which may be a limitation of the present study. Almost all of the included studies are in vitro and presented considerable heterogeneity in determining the virucidal efficacy using CHX. Therefore, the clinical applicability of results detected may be limited, and this must be considered when interpreting the results presented. However, the present study performed a broader search in the literature about the virucidal efficacy of CHX in all forms and concentrations. In addition, no restriction to language and date of publication was imposed, which are the main strengths of this systematic review. The interpretation of the findings should be performed considering the date of search and a continuous update in the literature is recommended.

In conclusion, CHX may present an interesting virucidal efficacy against HSV-1 and Influenza A viruses. However, reductions of $\mathrm{HCoV}$ and SARS-CoV-2 strains, when assessed in vitro, have not yet been demonstrated. In addition, rising with CHX may temporarily reduce the viral load of SARSCoV-2 in patients with COVID-19.

\section{Appendix 1}

Table 3. 
Table 3 Search strategy and number of studies detected in each all database

\begin{tabular}{|c|c|c|}
\hline Database & Search strategy & $\begin{array}{l}\text { Number } \\
\text { of stud- } \\
\text { ies }\end{array}$ \\
\hline PubMed & $\begin{array}{l}\text { \#1 Chlorhexidine[Mesh Terms] OR Chlorhexidine[Title/abstract] OR Biguanides[MeSH Terms] OR } \\
\text { Biguanides[Title/abstract] OR chlorhexidine gluconate[Supplementary Concept] OR Mouthwashes[Mesh } \\
\text { Terms] OR mouthwashes[Title/abstract] OR mouthrinses[Title/abstract] OR “mouthwash”[Title/abstract] OR } \\
\text { "mouthrinse"[Title/abstract] OR Anti-Infective Agents, Local[Mesh Terms] OR Local anti-infective agents[Title/ } \\
\text { abstract] OR Tubulicid[Title/abstract] OR Novalsan[Title/abstract] OR Sebidin A[Title/abstract] } \\
\text { \#2 COVID-19[Supplementary Concept] OR COVID-19[Title/abstract] OR Coronavirus[Mesh Terms] OR } \\
\text { Coronavirus[Title/abstract] OR Coronaviruses[Title/abstract] OR Coronaviridae[Title/abstract] OR Coronavirus } \\
\text { Infections[Mesh Term] OR Coronavirus Infections[Title/abstract] OR Virus Inactivation[Mesh Terms] OR Virus } \\
\text { Inactivation[Title/abstract] OR Virucidal[Title/abstract] OR Viral Inactivation[Title/abstract] OR virucide[Title/ } \\
\text { abstract] OR SARS-CoV-2[Title/abstract] OR virusa[Title/abstract] OR viruses[Mesh Terms] OR viruses[Title/ } \\
\text { abstract] OR viral load[Mesh Terms] OR viral load[Title/abstract] OR virus cultivation[Mesh Terms] OR virus } \\
\text { cultivation[Title/abstract] OR viral cultivation[Title/abstract] OR viral[Title/abstract] OR virology[Title/abstract] } \\
\text { OR Viral Burden[Title/abstract] } \\
\text { \#3-\#1 AND \#2 }\end{array}$ & 1225 \\
\hline Scopus & $\begin{array}{l}\text { ((TITLE-ABS-KEY("Hydrogen Peroxide") OR TITLE-ABS-KEY(H2O2) OR TITLE-ABS-KEY(Hydroperoxide) } \\
\text { OR TITLE-ABS-KEY(Peroxides) OR TITLE-ABS-KEY(Superoxol) OR TITLE-ABS-KEY(Oxydol) OR TITLE- } \\
\text { ABS-KEY(Perhydrol))) and ((TITLE-ABS-KEY(COVID-19) OR TITLE-ABS-KEY(Coronavirus) OR TITLE- } \\
\text { ABS-KEY(Coronaviruses) OR TITLE-ABS-KEY(Coronaviridae) OR TITLE-ABS-KEY("Virus Inactivation") } \\
\text { OR TITLE-ABS-KEY(Virucidal) OR TITLE-ABS-KEY("Viral Inactivation") OR TITLE-ABS-KEY(virucide) } \\
\text { OR TITLE-ABS-KEY(SARS-CoV-2) OR TITLE-ABS-KEY("viral load") OR TITLE-ABS-KEY("virus cultiva- } \\
\text { tion") OR TITLE-ABS-KEY(viral) OR TITLE-ABS-KEY("Viral Burden"))) }\end{array}$ & 1741 \\
\hline Web of Science & 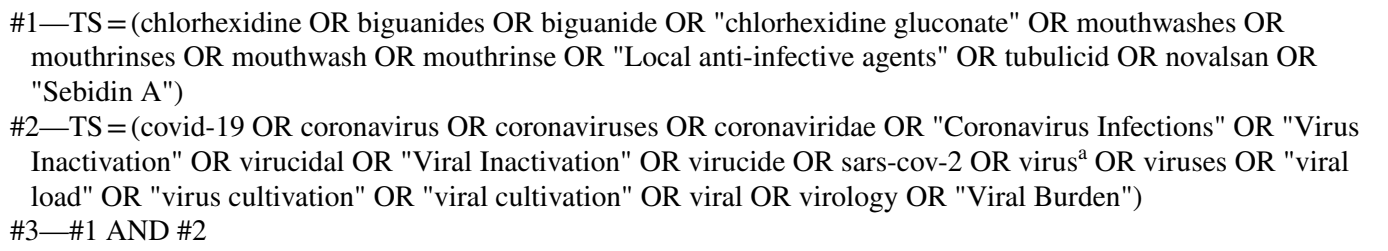 & 351 \\
\hline Embase & $\begin{array}{l}\text { \#1—chlorhexidine OR biguanides OR biguanide OR "chlorhexidine gluconate" OR mouthwashes OR mouthrinses } \\
\text { OR mouthwash OR mouthrinse OR "Local anti-infective agents" OR tubulicid OR novalsan OR "Sebidin A" } \\
\text { \#2—covid-19 OR coronavirus OR coronaviruses OR coronaviridae OR "Coronavirus Infections" OR "Virus Inac- } \\
\text { tivation" OR virucidal OR "Viral Inactivation" OR virucide OR sars-cov-2 OR virus }{ }^{\text {a }} \text { OR viruses OR "viral load" } \\
\text { OR "virus cultivation" OR "viral cultivation" OR viral OR virology OR "Viral Burden" } \\
\text { \#3—\#1 AND \#2 }\end{array}$ & 1562 \\
\hline Total & & 4879 \\
\hline Duplicates & & 2217 \\
\hline
\end{tabular}

${ }^{\text {a }}$ Search strategy performed on July 9th, 2021

Author contributions Conceptualization: MIFG, CKR, JC, and FWMGM. Methodology: CKR, JC, and FWMGM. Formal analysis and investigation: MSF, MIFG, GPJL, and FWMGM. Writing —original draft preparation: MSF and FWMGM. Writing - review and editing: MSF, MIFG, GPJL, CKR, JC, and FWMGM. Supervision: FWMGM and MIFG.

Funding This study was self-funded.

Availability of data and material Data we will forward upon request.

Code availability Not applicable.

\section{Declarations}

Conflict of interest The authors report no conflict of interest related to this study.
Ethical approval Not applicable.

Consent to participate Not applicable.

Consent for publication Not applicable.

\section{References}

1. Arteagoitia I, Rodriguez Andrés C, Ramos E. Does chlorhexidine reduce bacteremia following tooth extraction? A systematic review and meta-analysis. PLoS One. 2018;13: e0195592. https://doi.org/10.1371/journal.pone.0195592.

2. Rosenberg A, Alatary SD, Peterson AF. Safety and efficacy of the antiseptic chlorhexidine gluconate. Surg Gynecol Obstet. 1976;143:789-92. 
3. McDonnell G, Russell AD. Antiseptics and disinfectants: activity, action, and resistance. Clin Microbiol Rev. 1999;12:147-79.

4. Milstone AM, Passaretti CL, Perl TM. Chlorhexidine: expanding the armamentarium for infection control and prevention. Clin Infect Dis. 2008;46:274-81. https://doi.org/10.1086/ 524736.

5. Popovich KJ, Lyles R, Hayes R, et al. Relationship between chlorhexidine gluconate skin concentration and microbial density on the skin of critically ill patients bathed daily with chlorhexidine gluconate. Infect Control Hosp Epidemiol. 2012;33:889-96. https://doi.org/10.1086/667371.

6. James P, Worthington HV, Parnell C, et al. Chlorhexidine mouthrinse as an adjunctive treatment for gingival health. Cochrane Database Syst Rev. 2017;3: Cd008676. https://doi. org/10.1002/14651858.CD008676.pub2.

7. Afennich F, Slot DE, Hossainian N, Van der Weijden GA. The effect of hexetidine mouthwash on the prevention of plaque and gingival inflammation: a systematic review. Int J Dent Hyg. 2011;9:182-90. https://doi.org/10.1111/j.1601-5037.2010. 00478.x.

8. Zhao $\mathrm{H}, \mathrm{Hu}$ J, Zhao L. Adjunctive subgingival application of Chlorhexidine gel in nonsurgical periodontal treatment for chronic periodontitis: a systematic review and meta-analysis. BMC Oral Health. 2020;20:34. https://doi.org/10.1186/s12903-020-1021-0.

9. Sharma K, Acharya S, Verma E, Singhal D, Singla N. Efficacy of chlorhexidine, hydrogen peroxide and tulsi extract mouthwash in reducing halitosis using spectrophotometric analysis: a randomized controlled trial. J Clin Exp Dent. 2019;11:e457-63. https://doi.org/10.4317/jced.55523.

10. Fedorowicz Z, Aljufairi H, Nasser M, Outhouse TL, Pedrazzi V. Mouthrinses for the treatment of halitosis. Cochrane Database Syst Rev. 2008. https://doi.org/10.1002/14651858.CD006701. pub2.

11. Richards D. Chlorhexidine mouthwash plaque levels and gingival health. Evid Based Dent. 2017;18:37-8. https://doi.org/10.1038/ sj.ebd.6401232.

12. Flötra L, Gjermo P, Rölla G, Waerhaug J. Side effects of chlorhexidine mouth washes. Scand J Dent Res. 1971;79:119-25. https:// doi.org/10.1111/j.1600-0722.1971.tb02001.x.

13. Bescos R, Ashworth A, Cutler C, et al. Effects of chlorhexidine mouthwash on the oral microbiome. Sci Rep. 2020;10:5254. https://doi.org/10.1038/s41598-020-61912-4.

14. Marui VC, Souto MLS, Rovai ES, Romito GA, Chambrone L, Pannuti CM. Efficacy of preprocedural mouthrinses in the reduction of microorganisms in aerosol: a systematic review. J Am Dent Assoc. 2019;150:1015-26.e1. https://doi.org/10.1016/j.adaj.2019. 06.024 .

15. Jones CG. Chlorhexidine: is it still the gold standard? Periodontol 2000. 1997;15:55-62. https://doi.org/10.1111/j.1600-0757.1997. tb00105.x.

16. Page M, Moher D, Bossuyt P, et al. PRISMA 2020 explanation and elaboration: updated guidance and exemplars for reporting systematic reviews. BMJ. 2021;372: n160. https://doi.org/10. 1136/bmj.n160.

17. Karpiński TM, Szkaradkiewicz AK. Chlorhexidine-pharmacobiological activity and application. Eur Rev Med Pharmacol Sci. 2015;19:1321-6.

18. Koletsi D, Belibasakis GN, Eliades T. Interventions to reduce aerosolized microbes in dental practice: a systematic review with network meta-analysis of randomized controlled trials. J Dent Res. 2020;99:1228-38. https://doi.org/10.1177/0022034520943574.

19. Assis MS, Araújo R, Lopes AMM. Safety alert for hospital environments and health professional: chlorhexidine is ineffective for coronavirus. Rev Assoc Med Bras (1992). 2020;66Suppl 2:124-9. https://doi.org/10.1590/1806-9282.66.S2.124.
20. Joanna Briggs Institute. Joanna Briggs Institute reviewers' manual: 2014 edition. Australia: The Joanna Briggs Institute; 2014.

21. Krithikadatta J, Gopikrishna V, Datta M. CRIS guidelines (checklist for reporting in-vitro studies): a concept note on the need for standardized guidelines for improving quality and transparency in reporting in-vitro studies in experimental dental research. J Conserv Dent. 2014;17:301-4. https://doi.org/10.4103/0972-0707. 136338.

22. Sterne JAC, Savović J, Page MJ, et al. RoB 2: a revised tool for assessing risk of bias in randomised trials. BMJ. 2019;366: 14898. https://doi.org/10.1136/bmj.14898.

23. Bailey A, Longson M. Virucidal activity of chlorhexidine on strains of Herpesvirus hominis, poliovirus, and adenovirus. J Clin Pathol. 1972;25:76.

24. Baqui AA, Kelley JI, Jabra-Rizk MA, Depaola LG, Falkler WA, Meiller TF. In vitro effect of oral antiseptics on human immunodeficiency virus- 1 and herpes simplex virus type 1 . J Clin Periodontol. 2001;28:610-6. https://doi.org/10.1034/j.1600-051x. 2001.028007610.x.

25. Damery B, Cremieux A. Virucidal activity against Herpes and Vaccinia virus of 8 antiseptic formulations. Int $\mathbf{J}$ Pharmaceut. 1989;49:205-8.

26. Park N-H, Park JB, Min B-M, Cherrick HM. Combined synergistic antiherpetic effect of acyclovir and chlorhexidine in vitro. Oral Sur Oral Med Oral Pathol. 1991;71:193-6. https://doi.org/ 10.1016/0030-4220(91)90467-q.

27. Park JB, Park N-H. Effect of chlorhexidine on the in vitro and in vivo herpes simplex virus infection. Oral Sur Oral Med Oral Pathol. 1989;67:149-53. https://doi.org/10.1016/0030-4220(89) 90320-4.

28. Shinkai K, Yoshino K. Different sensitivities of type 1 and type 2 Herpes simplex virus to sodium p-chloromercuribenzoate and chlorhexidine gluconate. Proc Soc Exp Biol Med. 1974;147:201-4. https://doi.org/10.3181/00379727-147-38311.

29. Tyler R, Ayliffe G. A surface test for virucidal activity of disinfectants: preliminary study with herpes virus. J Hosp Infect. 1987;9:22-9. https://doi.org/10.1016/0195-6701(87)90090-9.

30. Okunishi J, Nishihara Y, Maeda S, Ikeda M. In vitro evaluation of the antimicrobial activity of HM-242, a novel antiseptic compound. J Antibiot. 2009;62:489-93. https://doi.org/10.1038/ja. 2009.56.

31. Bernstein D, Schiff G, Echler G, Prince A, Feller M, Briner W. In vitro virucidal effectiveness of a $0.12 \%$-chlorhexidine gluconate mouthrinse. J Dent Res. 1990;69:874-6. https://doi.org/10.1177/ 00220345900690030901.

32. Kawana R, Kitamura T, Nakagomi O, et al. Inactivation of human viruses by povidone-iodine in comparison with other antiseptics. Dermatology. 1997;195Suppl 2:29-35. https://doi.org/10.1159/ 000246027.

33. Ansaldi F, Banfi F, Morelli P, et al. SARS-CoV, influenza A and syncitial respiratory virus resistance against common disinfectants and ultraviolet irradiation. J Prev Med Hyg. 2004;45:5-8.

34. Geller C, Fontanay S, Finance C, Duval REA. new Sephadexbased method for removing microbicidal and cytotoxic residues when testing antiseptics against viruses: experiments with a human coronavirus as a model. J Virol Methods. 2009;159:21726. https://doi.org/10.1016/j.jviromet.2009.03.023.

35. Sattar SA, Springthorpe VS, Karim Y, Loro P. Chemical disinfection of non-porous inanimate surfaces experimentally contaminated with four human pathogenic viruses. Epidemiol Infec. 1989;102:493-505. https://doi.org/10.1017/s0950268800030211.

36. Imai K, Hagi A, Yamagawa S, Sano D. Olanexidine gluconate formulations as environmental disinfectants for enveloped viruses infection control. J Hosp Infect. 2021;112:37-41. https://doi.org/ 10.1016/j.jhin.2021.03.014. 
37. Meister TL, Brüggemann Y, Todt D, et al. Virucidal efficacy of different oral rinses against severe acute respiratory syndrome coronavirus 2. J Infect Dis. 2020;222:1289-92. https://doi.org/ 10.1093/infdis/jiaa471.

38. Xu C, Wang A, Hoskin ER, et al. Differential effects of antiseptic mouth rinses on SARS-CoV-2 infectivity in vitro. Pathogens. 2021;10:272. https://doi.org/10.3390/pathogens10030272.

39. Seneviratne CJ, Balan P, Ko KKK, et al. Efficacy of commercial mouth-rinses on SARS-CoV-2 viral load in saliva: randomized control trial in Singapore. Infection. 2020;2020:1-7. https://doi. org/10.1007/s15010-020-01563-9.

40. Davies K, Buczkowski H, Welch SR, et al. Effective in vitro inactivation of SARS-CoV-2 by commercially available mouthwashes. J Gen Virol. 2021;102: 001578. https://doi.org/10.1099/jgv.0. 001578.

41. Eduardo FP, Corrêa L, Heller D, et al. Salivary SARS-CoV-2 load reduction with mouthwash use: a randomized pilot clinical trial. Heliyon. 2021;7: e07346. https://doi.org/10.1016/j.heliyon.2021. e07346.

42. Elzein R, Abdel-Sater F, Fakhreddine S, et al. In vivo evaluation of the virucidal efficacy of chlorhexidine and povidone-iodine mouthwashes against salivary SARS-CoV-2. A randomized-controlled clinical trial. J Evid Based Dent Pract. 2021. https://doi. org/10.1016/j.jebdp.2021.101584.

43. Huang YH, Huang JT. Use of chlorhexidine to eradicate oropharyngeal SARS-CoV-2 in COVID-19 patients. J Med Virol. 2021;93:4370-3. https://doi.org/10.1002/jmv.26954.

44. Jain A, Grover V, Singh C. Chlorhexidine: an effective anticovid mouth rinse. J Indian Soc Periodontol. 2021;25:86-8. https://doi. org/10.4103/jisp.jisp_824_20.

45. Komine A, Yamaguchi E, Okamoto N, Yamamoto K. Virucidal activity of oral care products against SARS-CoV-2 in vitro. J Oral Maxillofac Surg Med Pathol. 2021;33:475-7. https://doi.org/10. 1016/j.ajoms.2021.02.002.

46. Steinhauer K, Meister TL, Todt D. Comparison of the in-vitro efficacy of different mouthwash solutions targeting SARSCoV-2 based on the European Standard EN 14476. J Hosp Infect. 2021;111:180-3. https://doi.org/10.1016/j.jhin.2021.01.031.

47. Hirose R, Bandou R, Ikegaya H, et al. Disinfectant effectiveness against SARS-CoV-2 and influenza viruses present on human skin: model-based evaluation. Clin Microbiol Infect. 2021;27(1042):e1-4. https://doi.org/10.1016/j.cmi.2021.04.009.

48. Villar CC, Pannuti CM, Nery DM, Morillo CM, Carmona MJ, Romito GA. Effectiveness of intraoral chlorhexidine protocols in the prevention of ventilator-associated pneumonia: meta-analysis and systematic review. Respir Care. 2016;61:1245-59. https://doi. org/10.4187/respcare.04610.

49. Wade RG, Burr NE, McCauley G, Bourke G, Efthimiou O. The comparative efficacy of chlorhexidine gluconate and povidoneiodine antiseptics for the prevention of infection in clean surgery: a systematic review and network meta-analysis. Ann Surg. 2020. https://doi.org/10.1097/SLA.0000000000004076.

50. Ogah CO, Anikwe CC, Ajah LO, et al. Pre-operative vaginal cleansing with chlorhexidine solution in preventing post-cesarean section infections in a low resource setting: a randomized controlled trial. Acta Obstet Gynecol Scand. 2021. https://doi.org/ 10.1111/aogs.14060.

51. Looker KJ, Welton NJ, Sabin KM, et al. Global and regional estimates of the contribution of herpes simplex virus type 2 infection to HIV incidence: a population attributable fraction analysis using published epidemiological data. Lancet Infect Dis. 2020;20:2409. https://doi.org/10.1016/S1473-3099(19)30470-0.

52. Thangavelu A, Kaspar SS, Kathirvelu RP, Srinivasan B, Srinivasan S, Sundram R. Chlorhexidine: an elixir for periodontics. J Pharm Bioallied Sci. 2020;12:S57-9. https://doi.org/10.4103/ jpbs.JPBS_162_20.
53. James C, Harfouche M, Welton NJ, et al. Herpes simplex virus: global infection prevalence and incidence estimates, 2016. Bull World Health Organ. 2020;98:315-29. https://doi.org/10.2471/ BLT.19.237149.

54. Chi CC, Wang SH, Delamere FM, Wojnarowska F, Peters MC, Kanjirath PP. Interventions for prevention of herpes simplex labialis (cold sores on the lips). Cochrane Database Syst Rev. 2015;2015: CD010095. https://doi.org/10.1002/14651858.CD010 095.pub2.

55. Kalonda A, Saasa N, Nkhoma $P$, et al. Avian influenza viruses detected in birds in sub-Saharan Africa: a systematic review. Viruses. 2020;12:993. https://doi.org/10.3390/v12090993.

56. Wong JY, Kelly H, Cheung CM, et al. Hospitalization fatality risk of influenza $\mathrm{A}(\mathrm{H} 1 \mathrm{~N} 1)$ pdm09: a systematic review and metaanalysis. Am J Epidemiol. 2015;182:294-301. https://doi.org/10. 1093/aje/kwv054.

57. Bilder L, Machtei EE, Shenhar Y, Kra-Oz Z, Basis F. Salivary detection of H1N1 virus: a clinical feasibility investigation. J Dent Res. 2011;90:1136-9. https://doi.org/10.1177/0022034511 413283.

58. da Silva PM, Sipert CR, Nogueira FN. Are the salivary glands the key players in spreading COVID-19 asymptomatic infection in dental practice? J Med Virol. 2020;93:204-5. https://doi.org/ 10.1002/jmv.26316.

59. Elisetti N. Periodontal pocket and COVID-19: could there be a possible link? Med Hypotheses. 2021;146: 110355. https://doi. org/10.1016/j.mehy.2020.110355.

60. Abasiyanik MF, Flood B, Lin J, et al. Sensitive detection and quantification of SARS-CoV-2 in saliva. Sci Rep. 2021;11:12425. https://doi.org/10.1038/s41598-021-91835-7.

61. Medeiros da Silva RC, Nogueira Marinho LC, de Araújo Silva DN, Costa de Lima K, Pirih FQ, de Aquino L, Martins AR. Saliva as a possible tool for the SARS-CoV-2 detection: a review. Travel Med Infect Dis. 2020;38: 101920. https://doi.org/10.1016/j.tmaid. 2020.101920.

62. Yoon JG, Yoon J, Song JY, et al. Clinical Significance of a High SARS-CoV-2 Viral Load in the Saliva. J Korean Med Sci. 2020;35: e195. https://doi.org/10.3346/jkms.2020.35.e195.

63. Cimolai N. Efficacy of povidone-iodine to reduce viral load. Oral Dis. 2020;26:1832. https://doi.org/10.1111/odi.13557.

64. Santana LADM, Pinho JNA, de Albuquerque HIM, Souza LMA. Virucidal potential of $\mathrm{H}_{2} \mathrm{O}_{2}$ - based spray against SARS-CoV-2 and biosafety in a dental environment. Oral Dis. 2021. https://doi. org/10.1111/odi.13778.

65. Muniz FWMG, Cavagni J, Langa GPJ, Stewart B, Malheiros Z, Rösing CK. A systematic review of the effect of oral rinsing with H. Int J Dent. 2020;2020:8841722. https://doi.org/10.1155/2020/ 8841722.

66. Burton MJ, Clarkson JE, Goulao B, et al. Antimicrobial mouthwashes (gargling) and nasal sprays administered to patients with suspected or confirmed COVID-19 infection to improve patient outcomes and to protect healthcare workers treating them. Cochrane Database Syst Rev. 2020;9: CD013627. https://doi.org/ 10.1002/14651858.CD013627.pub2.

67. Van Strydonc DAC, Slot DE, Van der Velden U, Van der Weijden F. Effect of a chlorhexidine mouthrinse on plaque, gingival inflammation and staining in gingivitis patients: a systematic review. J Clin Periodontol. 2012;39:1042-55. https://doi.org/10.1111/j. 1600-051X.2012.01883.x.

Publisher's Note Springer Nature remains neutral with regard to jurisdictional claims in published maps and institutional affiliations. 